\title{
The Stability of the Social Participation of Children Identified as Having MLD and The Different Ways of Assessing and Diagnosing Such Children in Kuwait
}

\author{
Dr.Bader Alqallaf \\ the public authority for training and education - College of Basic Education, Kuwait
}

\begin{abstract}
This study addressed the stability of the social participation of children identified as having MLDISlow learning in mainstream primary schools in Kuwait. The study relies heavily on longitudinal and ethnographic approaches. Two mainstream primary schools agreed to participate, comprising 31 with MLD/slow learning in Kuwait. The results indicated that the children with slow learning displayed no social interaction or friendship with their non-SEN peers who showed little acceptance of slow learning children. The study indicates that, it is important for children with Slow Learning in Kuwait to be aware of the nature of social participation in their setting and may help them to choose, with the agreement of their parents, whether to join a special class or a mainstream class. It would be useful for the child to understand the social difficulties that may arise from joining the special class setting. It is also important for the non-SEN children to be aware of the social participation of their peers with SEN. Providing knowledge about the social difficulties of children with SEN may help nonSEN children to accept their peers with SEN
\end{abstract}

Keywords: inclusion - Social Participation - Children with Slow Learning - Kuwait 


\section{Introduction}

\section{What is social participation?}

'Social participation of students in regular primary education is the presence of positive social contact/ interaction between them and their classmates; acceptance of them by their classmates; social relationships/friendships between them and their classmates; and the students' perception that they are accepted by their classmates. (Koster et al., 2009, p. 135)

\section{Why social participation is important?}

Maximising the interaction among students, and the socialization of all students in general, are frequently central aims of inclusive education. Parents, for example, send their children with SEN to mainstream schools in order to increase the number of social opportunities and their social participation (Scheepstra, Nakken \& Pijl, 1999). According to Koster, parents believe that it is essential for their children to grow in a 'normal' environment and they assume that social interaction with their peers will positively influence their children (Koster et al., 2007).

\section{Gaps in the area of social participation}

- So far, not much known about the stability of social participation (change over time)

- There are no much qualitative research in the area of Social Participation

- Yet, the concept of MLD is not clear and more research needed in this area of SEN

- Little research compared the concept of MLD across different cultures 


\section{Research design}

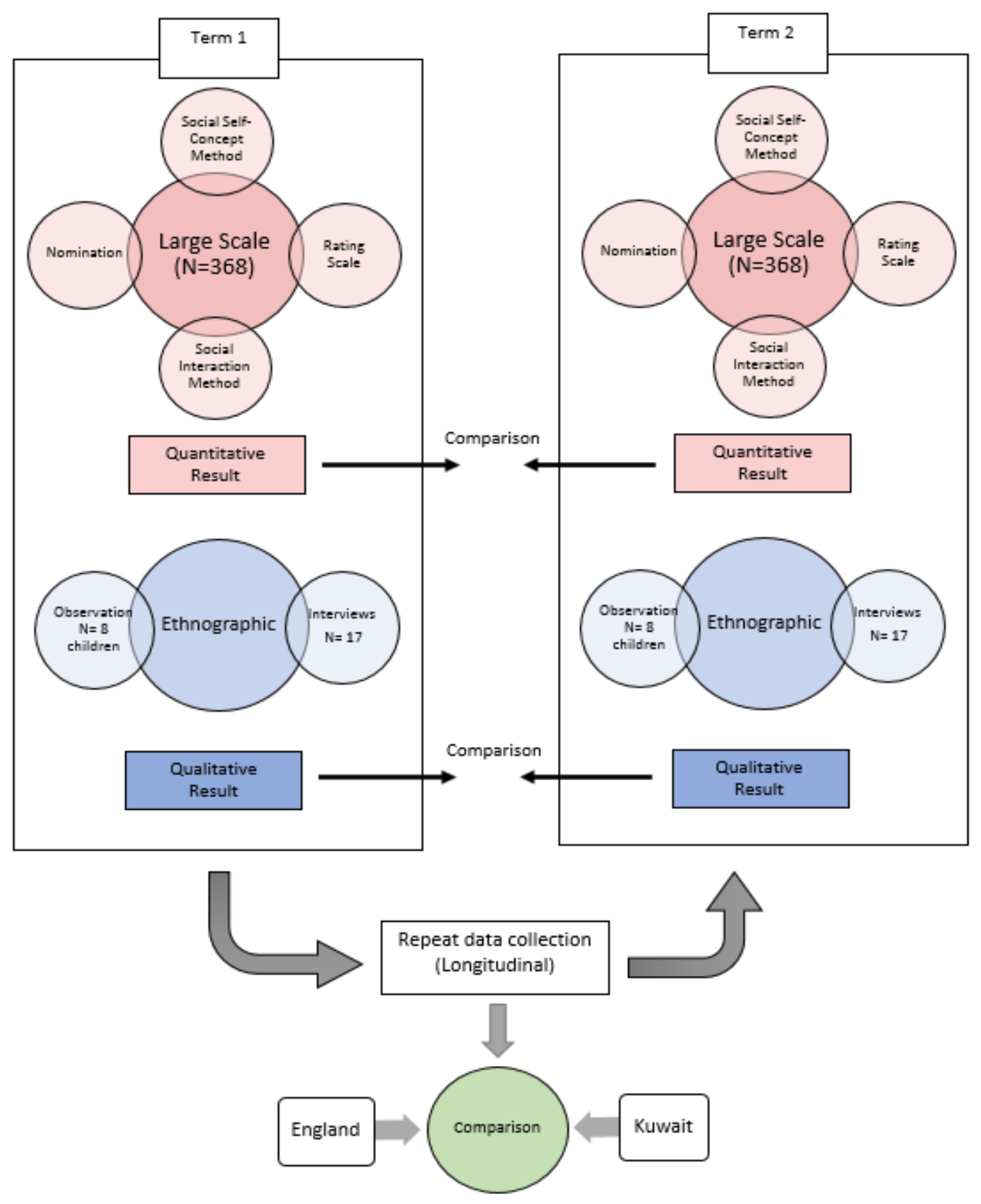




\begin{tabular}{|c|c|c|}
\hline \multicolumn{3}{|c|}{ Social participation In Kuwait and England } \\
\hline Research questions & What have b & een done \\
\hline \multirow[b]{2}{*}{$\begin{array}{l}\text { Does a difference in the four } \\
\text { dimensions of social } \\
\text { participation (i.e., friendship, } \\
\text { peer acceptance, social self- } \\
\text { concept and social interaction) } \\
\text { exist between MLD children } \\
\text { and their non-SEN peers in } \\
\text { mainstream primary schools? }\end{array}$} & Method used & Participants \\
\hline & 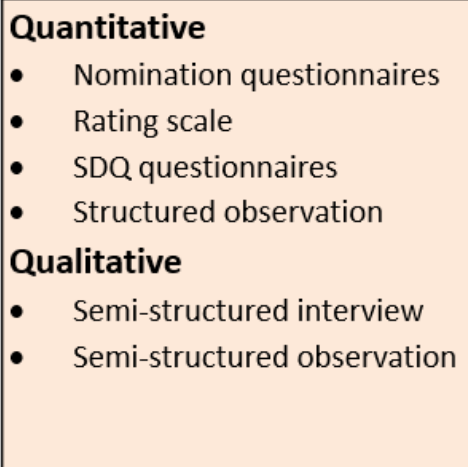 & $\begin{array}{l}\text { IN England } \\
\text { - } 22 \text { MLD, } 194 \text { non-SEN } \\
\text { - } \quad 2 \text { Teacher } \\
\text { - In Kuwait } \\
\text { - } \quad 32 \text { MLD, } 175 \text { non-SEN } \\
\text { - } 4 \text { teachers }\end{array}$ \\
\hline $\begin{array}{l}\text { Does the four dimensions of } \\
\text { children designated as having } \\
\text { MLD stable over one school } \\
\text { year comparing with the } \\
\text { stability of social participation } \\
\text { of Non-SEN children? }\end{array}$ & The same methods above & The same participants \\
\hline
\end{tabular}

This research was based on two main phases, the first phase aimed to investigate the concept of MLD/Slow Learning in Kuwait and England. The investigation was based on interviews as the main method to answer the research questions in phase one. Finally, the findings of the two countries were compared to each other in a cross cultural approach the find out the extent of similarity or difference between Kuwait and England regarding the concepts of MLD/Slow Learning, as Figure 3 shows below. In the second phase of this research an investigation of the social participation of children identified as having MLD/Slow Learning took place in both countries. The investigation started with a large scale study of children using nomination methods and questionnaires followed by shadowing certain case study children identified as having MLD/Slow Learning in both 


\section{SIENAEDUCATION}

27-29 March, 2020

Oxford, United Kingdom

countries. The same procedures were repeated one more time on the same children to investigate the stability of social participation and, finally, a comparison between the results of the two countries was made.

\section{Timetable of data collection}

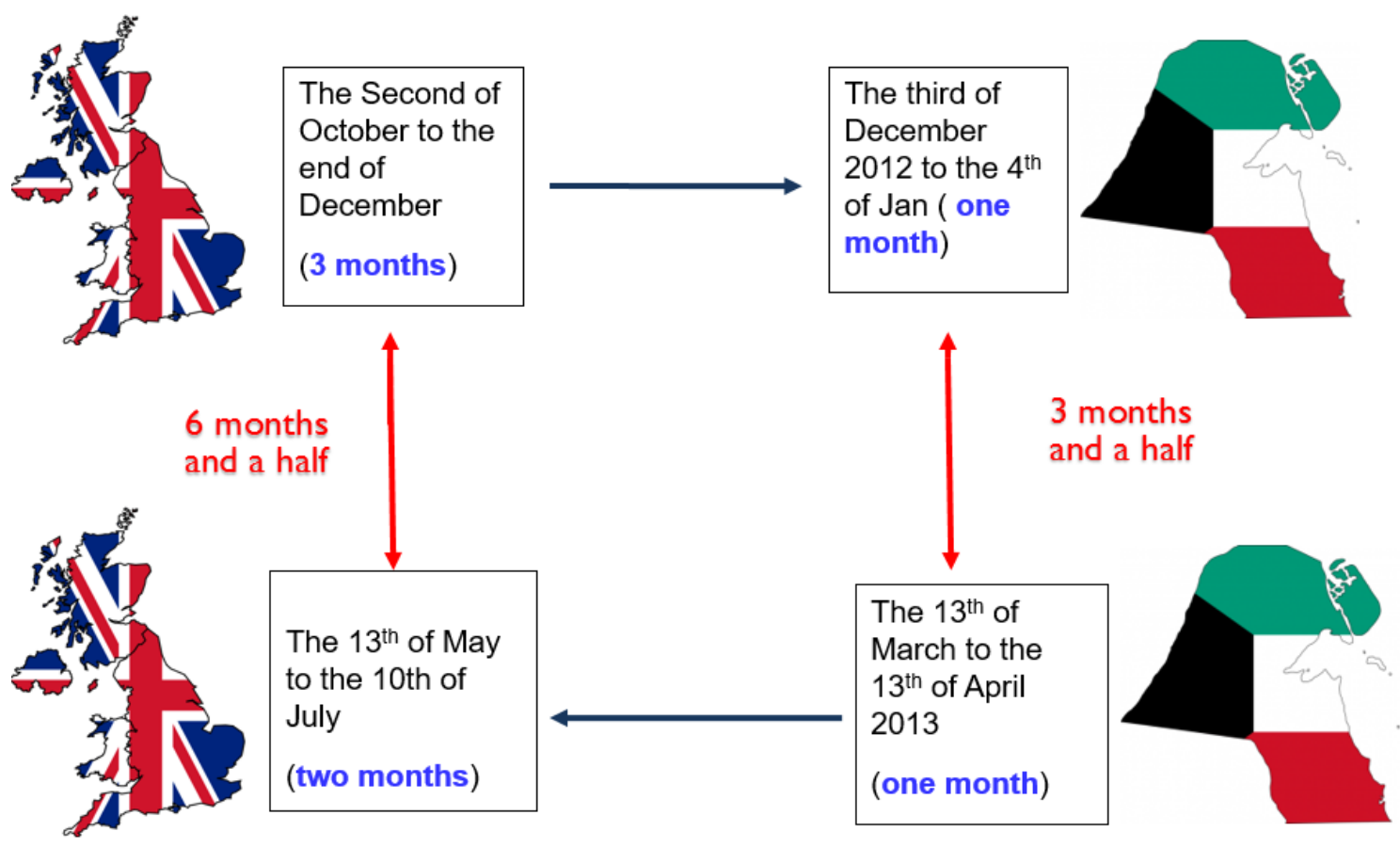




\section{Findings}

\begin{tabular}{|c|c|c|c|c|c|c|c|c|}
\hline \multicolumn{9}{|c|}{ Social self concept } \\
\hline \multicolumn{5}{|c|}{ First term } & \multicolumn{4}{|c|}{ Second term } \\
\hline & $\mathrm{N}$ & Mean & Std & Sig & $\mathrm{N}$ & Mean & Std & Sig \\
\hline MLD & 31 & 2.8746 & 1.00727 & \multirow{2}{*}{$\begin{array}{c}\text { Significant } \\
\text { difference } \\
(\mathrm{t}=6.072, \mathrm{df}=173 \mathrm{P}< \\
.05)\end{array}$} & 31 & 2.8459 & .80772 & \multirow{2}{*}{$\begin{array}{c}\text { Significant difference } \\
(t=5.431, d f=173, P< \\
.05)\end{array}$} \\
\hline Non-SEN & 144 & 3.7762 & 0.68380 & & 144 & 3.6605 & .74655 & \\
\hline
\end{tabular}
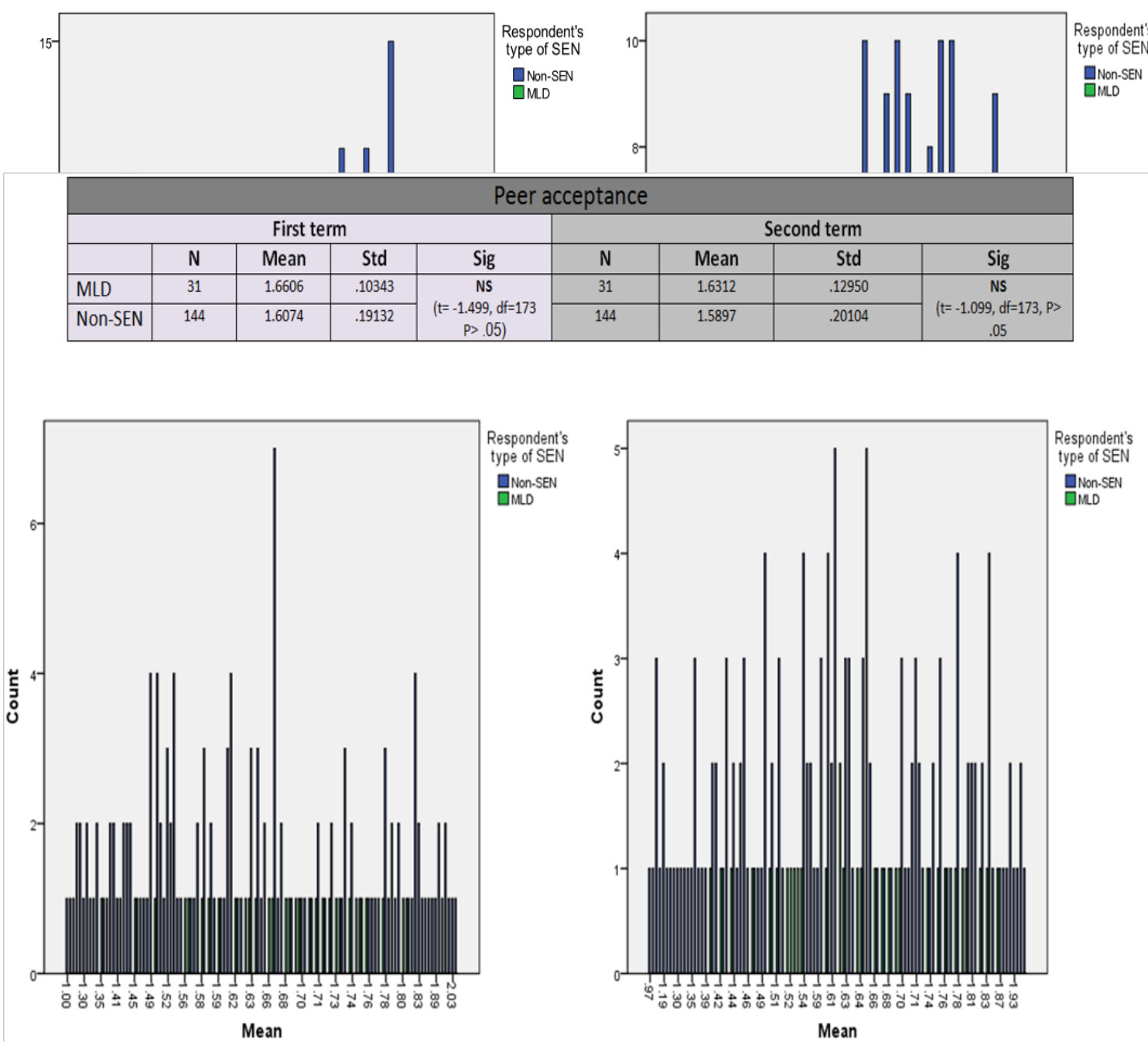


\begin{tabular}{|c|c|c|c|c|c|c|c|c|}
\hline \multicolumn{9}{|c|}{ Friendship } \\
\hline \multicolumn{5}{|c|}{ First term } & \multicolumn{4}{|c|}{ Second term } \\
\hline & $\mathrm{N}$ & Mean & Std & Sig & $\mathrm{N}$ & Mean & Std & Sig \\
\hline MLD & 31 & .1258 & .05150 & \multirow{2}{*}{$\begin{array}{c}\text { NS } \\
(t=-0,254, \mathrm{df}=172 \mathrm{P} \\
>.05)\end{array}$} & 31 & .1194 & .03741 & \multirow{2}{*}{$\begin{array}{c}\text { NS } \\
(t=0.140, d f=173, P> \\
.05)\end{array}$} \\
\hline Non-SEN & 144 & .1211 & .09980 & & 144 & .1214 & .08089 & \\
\hline
\end{tabular}

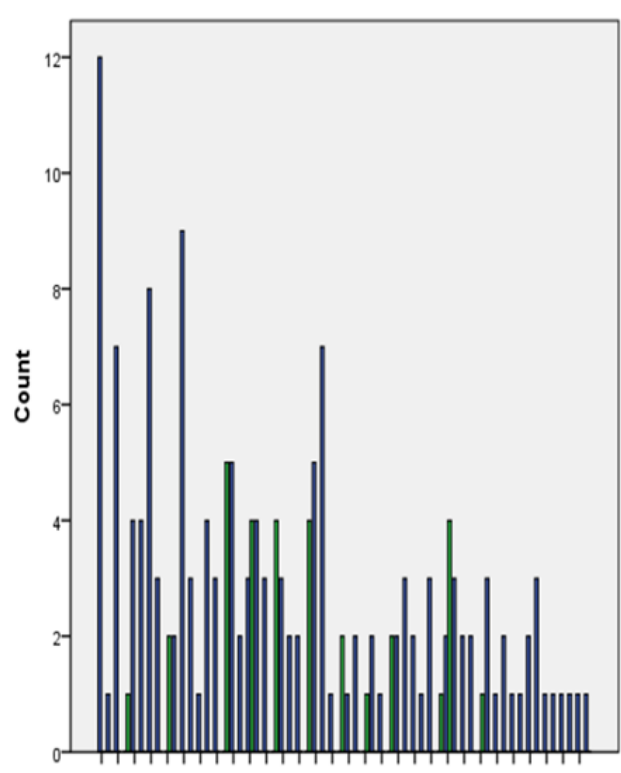

000303030505070808101111131314151617171819202224263030333842

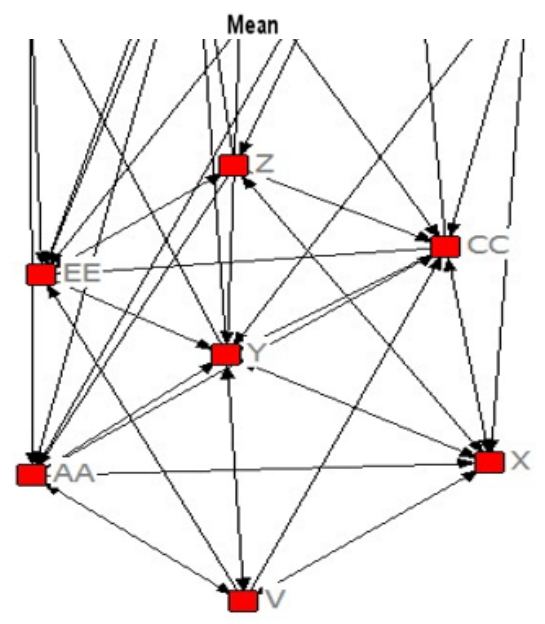

MLD special class group year 4
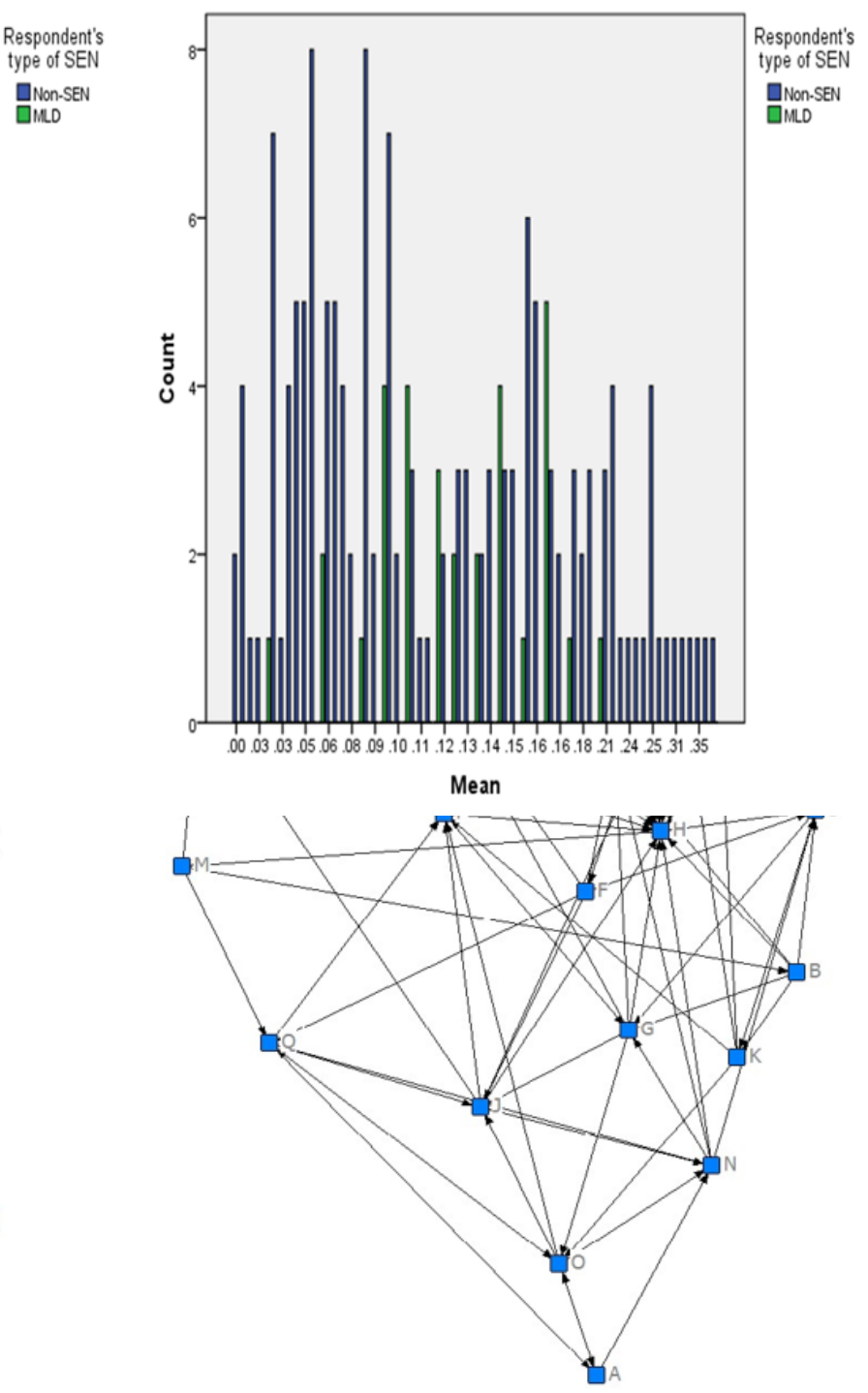

Non-SEN ordinary class year 4 


\section{Discussion and conclusion}

This study also has implications for the parents of children with and without MLD/Slow Learning. It is important for parents of children with MLD/Slow Learning to recognize some of the social difficulties that their children may face at school. Understanding the social participation of children in special classes may help the parents to take a more informed decision about the educational setting of their child, especially when Kuwaiti law allows parents to reject the idea of special classes and to keep their child in mainstream classes if they believe that this would be better for them. It is also important for the Kuwaiti Government to take into account that placing children in special classes may limit their Social Participation with their Peers.

\section{References:}

Avramidis, E. (2010). Social relationships of pupils with special educational needs in the mainstream primary class: Peer group membership and peer-assessed social behaviour. European Journal of Special Needs Education, 25(4), 413-429.

Avramidis, E. (2013) Self-concept, social position, and social participation of pupils with SEN in mainstream primary schools. Research Papers in Education, 28:4, 421-442.

Koster, M., Pijl, S. J., \& Nakken, H., \& Van Houten, E. J. (2010). Social participation of students with Special Needs in regular primary education in the Netherlands. International Journal of Disability, Development and Education, 57, 59-75.

Koster, M., Pijl, S. J., Van Houten, E. J., \& Nakken, H. (2007). The social position and development of pupils with SEN in mainstream Dutch primary school. European Journal of Special Needs Education, 22(1), 31-46.

Koster, M., Timmerman, M. E., Nakken, H., Pijl, S. J., \& Van Houten, E. J. (2009). Evaluating social participation of pupils with special needs in regular primary schools: Examination of a teacher questionnaire. European Journal of Psychological Assessment, $25,213-222$. 
Marsh, H.W. (1990). Self-description questionnaire 1 manual. Sydney, Australia: University of Western Sydney.

Norwich, B. (2013). Addressing tensions and dilemmas in inclusive education: Living with uncertainty. Routledge.

Warnock, M. (1978). Report of the Committee of Enquiry into the Education of Handicapped Children and Young People. London: HMSO.

Warnock, M. (2005). Special Educational Needs: A new look. London: Philosophy of Education Society of Great Britain.

Wellington, J. (2000). Educational research: Contemporary issues and practical approaches. London: Continuum. 